Caldeyro Barcia, R., and Alvarez, H. (1952). fournal of Obstetrics and Gynaecology of the British Empire, 59, 646.

Friedman, E. A., Niswander, K. R., Bayonet-Rivera, N. P., and Sachtleben, M. R. (1966). Obstetrics and Gynecology, 28, 495.

Fuchs, F., Fuchs, A. R., Poblete, V. F., and Risk, A. (1967). American fournal of Obstetrics and Gynecology, 99, 627

Karim, S. M. M. (1968). In Prostaglandins, Peptides and Amines, ed. P. Mantegazza and E. W. Horton, p. 65. London, Academic Press.

Karim, S. M. M. (1969a). Abstracts of 4th International Congress of Pharmacology, Basle, July, p. 337

Karim, S. M. M. (1969b). Prostaglandins and Kinins, R.S.M. Symposium, London, November.

Karim, S. M. M. (1970a). British Medical fournal, 3, 196.

Karim, S. M. M. (1970b). Conference on Prostaglandins, New York Academy of Sciences.
Karim, S. M. M. (1971). European fournal of Pharmacology. In press.

Karim, S. M. M., Hillier, K., Trussell, R. R., Patel, R. C., and Tamusange, S. (1970). Fournal of Obstetrics and Gynaecology of the British Commonwealth, 77, 200.

Karim, S. M. M., Sharma, S. D., Patel, J. R., and Trussell, R. R. (1971). fournal of Obstetrics and Gynaecology of the British Commonwealth. In press.

Karim, S. M. M., Trussell, R. R., Patel, R. C., and Hillier, K. (1968). British Medical fournal, 4, 621 .

Karim, S. M. M., Trussell, R. R., Hillier, K., and Patel, R. C. (1969). fournal of Obstetrics and Gynaecology of the British Commonwealth, 76, 769.

Karim, S. M. M., and Sharma, S. D. (1971). Fournal of Obstetrics and Gynaecology of the British Commonwealth. In press.

\title{
Candida Endocarditis Treated with 5-Fluorocytosine
}

\author{
C. O. RECORD, J. M. SKINNER，P. SLEIGHT， D. C. E. SPELLER
}

British Medical fournal, 1971, 1, 262-264

\section{Summary}

Three patients with endocarditis due to Candida species were treated with 5-fluorocytosine. One had endocarditis imposed on senile aortic sclerosis and survived and two had infections on prosthetic valves and died. In the latter two patients chemotherapy failed to eradicate the infection and was associated with marrow depression and possibly hepatic necrosis.

\section{Introduction}

Endocarditis caused by Candida species carries a very poor prognosis. Kay et al. (1968) reviewed 52 cases, of which 46 were fatal. Twenty-four of the patients had been treated with amphotericin B, but only five of these survived, one after surgical replacement of the valve when amphotericin B therapy had failed. The use of amphotericin B is often limited by thrombophlebitis at the sites of intravenous administration and by such toxic effects as fever, vomiting, and azotaemia (Louria et al., 1962). Recent reports of treatment of candida septicaemia and cryptococcal meningitis with the new antifungal agent 5-fluorocytosine (Tassel and Madoff, 1968; Watkins et al., 1969) encouraged us to use this drug for treatment of three patients with candida endocarditis, two of whom had infected prosthetic valves.

\section{Microbiological Methods}

Blood specimens were cultured by routine methods with aerobic and anaerobic pour plates and liquid cultures. In patients with prosthetic valves a pour plate was also prepared with glucose peptone agar; and in patients under treatment with antimicrobial agents a hypertonic liquid medium was inoculated for recovery of forms with impaired cell walls (Rosner, 1966; Watanakunakorn et al., 1968).

Minimum inhibitory concentrations (M.I.C.) and serum

Radcliffe Infirmary, Oxford

C. O. RECORD, M.B., M.R.C.P., Medical Registrar

J. M. SKINNER, M.B., CH.B., Lecturer in Pathology

P. SLEIGHT, M.D., F.R.C.P., Consultant Physician

D. C. E. SPELLER, M.R.C.P., M.R.C.PATH., Lecturer in Bacteriology

(Present address: Department of Bacteriology, University of Bristol) concentrations of 5-fluorocytosine were determined by the methods of Shadomy (1969). Species identification of the Candida strains and estimation of serum antibodies were carried out by Dr. I. G. Murray (Murray et al., 1969).

\section{Case 1}

A 57-year-old man was admitted to hospital with a suspected diagnosis of subacute bacterial endocarditis three months after aortic valve replacement with a Starr Edwards prosthesis. Blood cultures yielded $C$. parapsilosis and he was given amphotericin B $10 \mathrm{mg}$ daily, rising to $60 \mathrm{mg}$ daily one week later. After two weeks' therapy and a total dose of $590 \mathrm{mg}$ he had become afebrile, but because of progressive azotaemia (blood urea $130 \mathrm{mg} / 100 \mathrm{ml}$ ), multiple venous thromboses, and the patient's unwillingness to continue receiving the drug, it was stopped and 5-fluorocytosine was started in a dose of $8 \mathrm{~g}$ daily. He at once felt better, he remained afebrile, and there were no further embolic episodes. Microscopical haematuria continued, but his blood urea returned to normal.

He was sent home, very fit, and returned to work. His 5 fluorocytosine dose was reduced to $4.5 \mathrm{~g}$ daily because of gastrointestinal symptoms and laboratory evidence of liver damage (serum aspartate aminotransferase 48 units $/ 100 \mathrm{ml}$; lactate dehydrogenase 500 units $/ 100 \mathrm{ml}$; bromsulphthalein retention $28 \%$ at 45 minutes). His blood count remained normal (platelets $200,000 / \mathrm{mm}^{3}$, leucocytes $4,700 / \mathrm{mm}^{3}$ five weeks later).

Six weeks after discharge, however, he was readmitted with a purpuric rash, and examination of the peripheral blood showed thrombocytopenia and neutropenia. He developed a left hemiparesis and died three weeks later with irreversible marrow failure.

Necropsy Findings.-A large recent subdural haematoma was present. The heart was enlarged $(700 \mathrm{~g})$ and showed on adhesive pericarditis. Microscopically, irregular muscle hypertrophy and diffuse fibrosis were found but there was no evidence of recent muscle necrosis, and though significant atheroma was present there was no vascular occlusion. There was a small aneurysm on the aortic suture line. The Starr Edwards prosthesis in the aorta bore very small vegetations on the ventricular aspect in which fungal elements were seen on microscopy. Culture yielded $C$. albicans resistant to 5-fluorocytosine. There were a few mucosal haemorrhages throughout the alimentary tract. The liver was enlarged and congested with large irregular areas of softening. The blood vessels were normal. Microscopically, patchy liver cell necrosis and some collapse of the reticulin framework (largely periportal and midzonal in the lobule) were found. In addition, the Kupffer cells were strongly positive for iron and the liver cells moderately so. The bone marrow was hypoplastic and no megakaryocytes were seen. 


\section{Case 2}

A 62-year-old man developed endocarditis due to $C$. albicans eight days after mitral valve replacement with a Beale prosthesis. Treatment with 5-fluorocytosine $8 \mathrm{~g}$ daily was begun with good initial response. After two weeks of treatment his fever recurred, embolic phenomena reappeared, and amphotericin $\mathbf{B}$ was therefore added (10 mg daily rising to $60 \mathrm{mg}$ daily). Later the dose of 5-fluorocytosine was increased to $12 \mathrm{~g}$ daily, but he continued to deteriorate and the prosthesis was replaced by another on the 47 th postoperative day.

He had received a total of $264 \mathrm{~g}$ of 5 -fluorocytosine and $660 \mathrm{mg}$ of amphotericin B. Immediately before surgery his blood urea had risen to $87 \mathrm{mg} / 100 \mathrm{ml}$, the lactate dehydrogenase to 356 units/100 $\mathrm{ml}$, and bromsulphthalein retention to $30 \%$ at 45 minutes: other tests of liver function were normal. He had a normochromic anaemia $(9.9 \mathrm{~g} / 100 \mathrm{ml})$ and was given a blood transfusion. The reticulocytes were raised to $2.1 \%$ (compatible with some degree of haemolysis) and his white cells and platelets were normal at 6,000 and $170,000 / \mathrm{mm}^{3}$ respectively.

At operation vegetations were attached to the superior aspect of the valve cloth, while the atrium appeared free from infection. Culture of the vegetations yielded a profuse growth of $C$. albicans sensitive to 5-fluorocytosine.

Postoperatively amphotericin B (250 mg) and 5-fluorocytosine (12 $\mathrm{g}$ daily) were restarted. His serum bilirubin rose transiently and he became anaemic, requiring transfusion despite a reticulocytosis. He became very depressed, weak, and lethargic, and developed diarrhoea and pronounced oedema of the legs, with dehydration, hypovolaemia, and rise in serum sodium (150 mEq/1.) and chloride $(121 \mathrm{mEq} / 1$.). His blood urea rose, reaching $160 \mathrm{mo} / 100$ ml terminally. The transaminases were normal but the lactate dehydrogenase rose to 2,700 units $/ 100 \mathrm{ml}$, with isoenzymes 1 and 2 predominant. He died on the 19th postoperative day.

Necropsy Findings.- The brain was oedematous and the heart was hypertrophied $(608 \mathrm{~g})$. Over both aspects of the Beale prosthesis there was a fibrinous membrane; on the atrial side the valve was completely covered, but half of this membrane was thin and had probably formed after death; on the ventricular side half the valve was occluded. These membranes were largely fibrin webs with a few polymorphs and macrophages, Gram-negative bacilli, and fungi. Immediately below the prosthetic valve ring there was a rim of endocardial and subendocardial necrosis which was possibly related to surgical trauma. The coronary arteries were small and showed slight atheroma. Throughout the mvocardium there was patchy necrosis of the muscle fibres with replacement by loose fibrous tissue containing macrophages, lymphocytes, plasma cells, and Anitschkow cells in moderate numbers. The kidneys showed tubular necrosis. The liver was enlarged $(1,770 \mathrm{~g})$ and had a variable pale yellow appearance, with irregular, depressed, soft necrotic areas. Microscopically there were patchy liver cell necrosis and collapse of reticulin framework, largely midzonal and periportal in the lobule, but occasionally centrilobular. In some areas regeneration of cells could be seen with many binucleate forms. Large amounts of iron were found in the Kupffer and liver cells. Sections of bone marrow showed hypoplasia with extensive fat replacement; some megakaryocytes could be seen.

\section{Case 3}

A 73-year-old woman was admitted to another hospital drowsy, hypotensive, and febrile. She was thought to be suffering from aspiration pneumonia and was treated with ampicillin, hydrocortisone, intravenous fluids, and physiotherapy, with gradual improvement. A systolic murmur was noted before her discharge home.

She was readmitted nine weeks later with a history of fever, increasing drowsiness, and anaemia. Chest and urinary tract infections were suspected but she failed to respond to courses of antibiotics. Three weeks after admission she was still febrile, with nightly peaks to $104^{\circ} \mathrm{F}\left(40^{\circ} \mathrm{C}\right)$; widespread petechiae, retinal haemorrhages, and splenomegaly were present in addition to a soft early diastolic murmur. A diagnosis of infective endocarditis complicating senile calcific aortic sclerosis with incompetence was made, and blood and urine cultures yielded $C$. albicans.

Treatment with amphotericin B was started and $286 \mathrm{mg}$ was administered before this was stopped a week later because of nausea and thrombophlebitis. 5-Fluorocytosine $8 \mathrm{~g}$ daily was then administered to a total of $368 \mathrm{~g}$. Improvement began soon after starting amphotericin $B$ and had continued until the time of writing, the subsequent blood cultures being negative. Apart from some mild diarrhoea there was no evidence of side-effects of 5fluorocytosine.

\section{Microbiological Results}

Case 1.-C. parapsilosis (M.I.C. $0.12 \mu \mathrm{g}$ 5-fluorocytosine/ml) was isolated from seven blood specimens taken at separate times before treatment was started. Culture from three separate areas of the prosthetic valve and from blood clot related to it, at necropsy, all yielded $C$. albicans (resistant to 5-fluorocytosine-M.I.C. more than $1,000 \mu \mathrm{g} / \mathrm{ml}$ ). Sera showed precipitins to $C$. parapsilosis and a rising titre of agglutinins to that yeast. Precipitins were also demonstrable to $C$. albicans (weakly positive), $C$. tropicalis, and $C$. guilliermondii, and this pattern of antibodies is consistent with a diagnosis of candida endocarditis (Murray et al., 1969). Serum 5fluorocytosine concentrations ranged from 100 to $180 \mu \mathrm{g} / \mathrm{ml}$ in the first two weeks of treatment, but lower concentrations (40 to 45 $\mu \mathrm{g} / \mathrm{ml}$ ) were obtained later on the same dosage.

Case 2.-C. albicans (M.I.C. 0.25 $\mu \mathrm{g}$ 5-fluorocytosine/ml) was isolated from nine specimens of blood taken at different times before treatment was started. No growth was obtained from any subsequent blood culture. Culture of several separate vegetations from the resected prosthetic valve yielded $C$. albicans (M.I.C. $0.25 \mu \mathrm{g} 5$-fluorocytosine $/ \mathrm{ml}$ ). No yeasts were isolated from postmortem specimens (new prosthetic valve, endocardium, heart blood, lung). Throughout his illness his serum showed strongly positive precipitin tests and high titre agglutinins to four species of Candida (C. albicans, C. parapsilosis, $C$. tropicalis, and $C$. guilliermondii). Serum 5-fluorocytosine concentrations ranged from 20 to $40 \mu \mathrm{g} / \mathrm{ml}$ on $8 \mathrm{~g} \mathrm{5-fluorocytosine} \mathrm{daily,} \mathrm{and} \mathrm{from} 110$ to 130 $\mu \mathrm{g} / \mathrm{ml}$ on $12 \mathrm{~g}$ daily.

Case 3.-C. albicans (M.I.C. $0.12 \mu \mathrm{g}$ 5-fluorocytosine/ml) was isolated from four separate specimens of blood before treatment was started. No growth was obtained from any subsequent blood culture. Agglutinins to $C$. albicans at a titre of 1 in 128 were found and precipitin tests were strongly positive for $C$. albicans and $C$. guilliermondii and moderately positive $C$. parapsilosis. Serum 5-fluorocytosine concentrations ranged from 20 to 100 $\mu \mathrm{g} / \mathrm{ml}$.

\section{Discussion}

Candida infection of a prosthetic or homograft valve is an uncommon but dangerous complication of cardiac surgery. We know of only three reported cures of candida endocarditis associated with replacement valves. Conway et al. (1968) described the case of a patient who received an aortic homograft and developed candida infection 10 days after the operation, but was cured with prolonged amphotericin B therapy alone. E. J. Epstein (personal communication) reported a similar case of infection of an aortic hornograft. The patient was treated with amphotericin B and the homograft was replaced by a prosthesis. S. B. Shohet (personal communication) has recently treated a patient with candida endocarditis, associated with a Starr Edwards prosthesis, with 5-fluorocytosine with successful outcome. Even when candida endocarditis is not associated with a replacement valve cure with chemotherapy alone is unlikely.

5-Fluorocytosine is a selective antifungal agent which may be given orally. It was shown to have a pronounced effect on intravenous candida infection in mice (Grunberg et al., 1963) and (as stated in the introduction) there have been reports of its successful use in fungal infections in man.

Minimum inhibitory concentrations of 5-fluorocytosine reported for Candida species (Shadomy, 1969) ranged from 0.23 to $3.9 \mu \mathrm{g} / \mathrm{ml}$ with a few strains resistant to $1,000 \mu \mathrm{g} / \mathrm{ml}$. The action of the drug in vitro is almost entirely fungistatic, rather than fungicidal. Fungicidal concentrations of 
amphotericin B cannot be achieved in the serum by currently used doses (Louria and Dineen, 1960), and thus neither agent would appear ideal for the treatment of endocarditis, a condition requiring cidal activity for reliable therapeutic success.

In Cases 1 and 2 candida infection was still present at death and at valve resection, respectively. No fungi were cultured from post-mortem material in Case 2, though fungal elements were seen in the valve web. In Case 1 the organism recovered was a different species (C. albicans not $C$. parapsilosis) and resistant to 5-fluorocytosine, and this implies either a mixed infection from which the resistant strain was selected by treatment or possibly a secondary infection in the course of, or after discontinuation of, antifungal treatment. The serum antibodies do not suggest that $C$. albicans played a major part in the illness. In Case 2 the isolate from the resected valve after four weeks' treatment with 5-fluorocytosine was as sensitive to the drug as the original isolate. Case 3 recovered from the infection after receiving $286 \mathrm{mg}$ of amphotericin $\mathrm{B}$ followed by $368 \mathrm{~g}$ of 5-fluorocytosine. Though her fever responded to amphotericin B, this was not tolerated and she improved and remained afebrile on 5fluorocytosine.

The serum concentrations of 5-fluorocytosine in this series were generally higher than those previously reported (Shadomy, 1969). In Case 1 the high levels obtained at first may have been due to the damage to the kidneys by previous amphotericin B treatment and fell to lower levels later on the same dosage; but high levels were deliberately obtained in Case 2, because the clinical response was less satisfactory than that in Case 1 had been.

Experimental work and clinical use has suggested that the toxicity of 5-fluorocytosine is low. Raised transaminase levels, rashes, and transient leucopenia (Grunberg et al., 1967) and reversible pancytopenia (Miller, in Tassel and Madoff, 1968) have been reported. Toxic effects may be related to dosage and the length of time during which the drug is administered (Grunberg et al., 1967). The first of our patients died as a result of severe marrow hypoplasia, and the second showed evidence of marrow depression at necropsy. Both had liver neocrosis at necropsy. There have been reports of both liver necrosis (Carnecchia and Kurtzke, 1960) and marrow hypoplasia (Stein and Burdon, 1960) due to amphotericin B, and as Case 2 received this drug until eight days before his death it might have been responsible for the necropsy findings. In Case 1, however, no amphotericin $B$ had been administered in the three months before death, and it seems reasonable to attribute the marrow depression and hepatic necrosis to the action of 5-fluorocytosine. The pattern of necrosis seen in these livers was zonal and mainly periportal in type, and some of the remaining cells showed degenerative features in all stages, suggesting slow loss rather than rapid lysis. There was little evidence of regeneration of cells or bile duct hyperplasia or the development of cirrhosis. These features suggest a toxic rather than a viral aetiology (Popper and
Franklin, 1948) and are in contrast to the centrilobular changes seen in cardiac failure. Candida infection usually produces an acute suppurative focal hepatitis quite unlike the picture described.

Case 2 developed an itchy rash on his trunk while receiving 5-fluorocytosine which persisted when all other drugs were discontinued. All three patients suffered from mild abdominal pain and diarrhoea while receiving the drug. Case 2 had a massive rise in lactate dehydrogenase with isoenzymes 1 and 2 predominating, which suggests a cardiac or erythrocyte origin for the enzyme. At necropsy there was patchy but extensive cardiac necrosis.

Kay et al. (1968) suggest that fungal endocarditis demands a combined chemotherapeutic and surgical attack on the infected valve, and our disappointing results in Cases 1 and 2 support this view. 5-Fluorocytosine gave remarkable clinical improvement in all three patients, and the infection was eradicated in Case 3, suggesting that 5-fluorocytosine may be a useful antifungal agent in less intractable types of infection. The complications which we have encountered imply that prolonged treatment with high serum levels of 5-fluorocytosine may be dangerous, and the risks should be borne in mind while the use of this agent in systemic fungal infections is assessed further.

We are grateful to Dr Lorna Davies for permission to publish Case 3, to Dr. I. G. Murray for fungal identifications and antibody estimations, to Dr. P. Emerson for haematological investigations, and to Mr. G. Higgins for the lactate dehydrogenase isoenzyme estimations. 5-Fluorocytosine was provided by Roche Products, and Dr. J. Garrod advised on the use of the drug.

\section{References}

Carnecchia, B. M., and Kurtzke, J. F. (1960). Annals of Internal Medicine, $53,1027$.

Conway, N., Kothari, M. L., Lockey, E., and Yacoub, M. H. (1968). Thorax, 23, 353.

Grunberg, E., Prince, H. N., and Utz, J. P. (1967). In Proceedings of 5th International Congress of Chemotherapy Vienna, ed. K. H. Spitzy and International Congress of Chemotherapy Vienna, ed. K. H.
$\mathrm{H}$. Haschek, vol. 4, p. 69 . Vienna, Academy of Medicine.

Grunberg, E., Titsworth, E., and Bennett, M. (1963). Antimicrobial Agents and Chemotherapy, 3, 566.

Kay, J. H., et al. (1968). Fournal of the American Medical Association, 203,

Louria, D. B., and Dineen, P. (1960). Fournal of the American Medical Association, 174, 273.

Louria, D. B., Stiff, D. P., and Bennett, B. (1962). Medicine, 41, 307.

Murray, I. G., Buckley, H. R., and Turner, G. C. (1969). Fournal of Medical Microbiology, 2, 463 .

Popper, H., and Franklin, M. (1948). Archives of Pathology, 46, 338.

Rosner, R. (1966). Fournal of Bacteriology, 91, 1320.

Shadomy, S. (1969). Applied Microbiology, 17, 871.

Stein, J. M., and Burdon, P. J. (1960). Annals of Internal Medicine, 52, 445.

Tassel, D., and Madoff, M. A. (1968). Fournal of the American Medical Association, 206, 830 .

Association, 206, 830 .
Watanakunakorn, C., Carleton, J., Goldberg, L. M., and Hamburger, M. (1968). Archives of Internal Medicine, 121, 243.

Watkins, J. S., Campbell, M. J., Gardner-Medwin, D., Ingham, H. R., and Murray, I. G. (1969). British Medical fournal; 3, 29. 